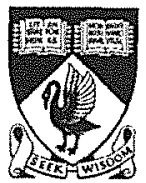

AN ANALYSIS OF THE IMPLICATIONS FOR THE GOLD MINING INDUSTRY OF ALTERNATIVE TAX POLICIES:

A REGIONAL DISAGGREGATED MODEL FOR AUSTRALIA

by

Andrew Feltenstein

DISCUSSION PAPER 97.25

DEPARTMENT OF ECONOMICS

THE UNIVERSITY OF WESTERN AUSTRALIA

NEDLANDS, WESTERN AUSTRALIA 6907

ISSN 0811-6067

ISBN 0-86422-823-6 


\title{
AN ANALYSIS OF THE IMPLICATIONS FOR THE GOLD MINING INDUSTRY OF ALTERNATIVE TAX POLICIES: \\ A REGIONAL DISAGGREGATED MODEL FOR AUSTRALIA
}

\author{
by \\ Andrew Feltenstein \\ Department of Economics \\ University of Virginia \\ Blacksburg, USA
}

DISCUSSION PAPER 97.25

October, 1997

ISSN 0811-6067

ISBN 0-86422-823-6 


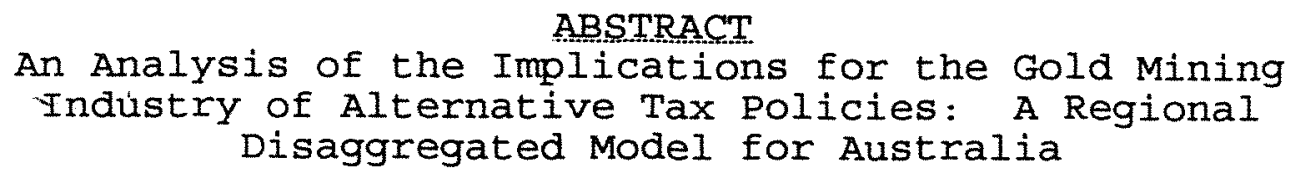

by

Andrew Feltenstein

Dept. of Economics

Virginia Tech

Blacksburg, VA 24061

USA

We construct a dynamic model of the Australian economy that has a regional sub-section representing Western Australia. Within the West Australia sub-economy, there is a separate technology for the gold mining industry.

We implement the model, and simulate a 2.5 percent tax on gold exports. The outcome shows no fiscal improvement at the national level, although the west Australian budget improves slightly. Real income falls both nationally and in west Australia as the trade balance deteriorates, and an increased real interest rate causes investment to fall. We conclude that the taxation of gold exports leads to few measurable benefits. 
An Analysis of the Implications for the Gold Mining Industry of Alternative Tax Policies: A Regional Disaggregated Model for Australia

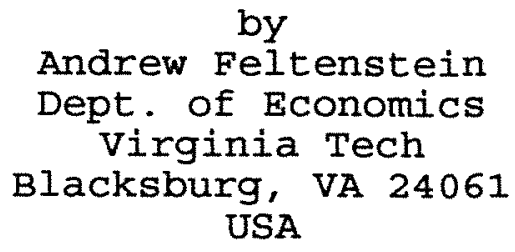

\section{Introduction}

This paper will analyze the implications for the Australian gold mining industry, as well as for the local and national economy, of a tax levy upon gold production. Since mining in general, and gold mining in particular, are of special importance to the state of Western Australia (WA), we will also closely examine the macroeconomic impact of these tax policies upon the economy of WA.

We incorporate a regional model of WA as an integrated part of our national model, which consists of WA and the rest of Australia, RA. We permit economic impacts to run both from the national level to WA, as well as in the opposite direction. The production structure of our model will incorporate considerable detail about the WA economy in general, and about the mining sector in particular.

The next section will briefly examine certain issues concerning the Australian gold mining industry. Section 3 will develop our model structure, while section 4 will carry out a 
series of numerical simulations. The final section will be a summary and conclusion.

II. Issues in the Australian Gold Mining Industry

Gold output has grown strongly in Australia in recent years. Production in WA rose by 4.7 percent in 1994. This represented about 74 percent of total Australian gold production, and about 8 percent of total world output. Indeed, only South Africa and the US produced more gold than Australia in 1994.

Gold has become especially important for the WA economy, and its current output value of $A \$ 3,257$ million now make it western Australia's highest valued mineral product. Almost 90 percent of Western Australia's gold output is exported, with the main importers being Japan and Singapore.

The WA government is currently considering enforcing a state royalty on gold production, primarily as a source of revenues. In particular, a 2.5 percent tax is currently being proposed. Gold is currently exempted from any such royalty. The most common rational for this tax is that like all other minerals, gold mining should pay a fee for the purchase of the ore from the state. Another reason appears to be the belief that the tax would have little, if any, economic effects. In other words, the supply elasticity of gold is relatively low. Given the importance of gold to the WA economy, and to Australia as a whole, the imposition of a tax on gold should be carefully examined. 
II . Model structure

Our model is a discrete time, perfect foresight general equilibrium system with an arbitrary number of time periods." We will confine ourselves to 2 periods for the description of the model. There is production technology at both the state, WA, and national level, RA. There are also capital and labor that are specific to the two parts of the country.

a. Production

There are 4 factors of production and three types of financial assets. These are:

Factors and Financial Assets

\begin{tabular}{|l|l|l|}
\hline 1. RA Capital & 4. Domestic Bonds & 7. WA Capital \\
\hline 2. RA Labor & 5. Foreign Currency & \\
\hline 3. Money & 6. WA Labor & \\
\hline
\end{tabular}

Intuitively, capital is specific to the two parts of the country, while labor can migrate from one part of the country to the other in search of higher wages. Investors may create capital in either part of the country, based on rates of return in the two regions.

An input-output matrix, A, represents intermediate and final production. The technology of this matrix is also sector specific so that it has the form: 


$$
\left[\begin{array}{cccc}
W A_{t} & X_{W A_{t}} & 0 & 0 \\
M_{W A_{t}} & A_{t} & 0 & 0 \\
0 & 0 & W A_{t+1} & X_{W A_{t+1}} \\
0 & 0 & M_{W A_{t+1}} & A_{t+1}
\end{array}\right]
$$

Here we make the following definitions.

WA denotes the WA input-output matrix.

A denotes the RA input-output matrix.

$M_{\text {w. }}$ denotes imports to WA from RA.

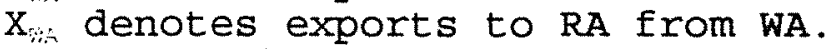

The subscripts $t, t+1$ denote time periods.

Thus in each period both the RA and WA economies produce output, using sector specific value added. Trade takes place between the two parts of the economy, and the intermediate and final products of each part of the country are distinct, although they may be similar.

We have two data sources for the production technology. The Australian input-output matrix is derived from Australian National Accounts: Input-Output Tables (1994). The WA matrix is taken from Clements and Qiang (1995), while interstate coefficients were derived from Lewis (1995) and Interstate and Foreign Trade: Western Australia (1990).

value added in the $j^{t:}$ sector in time $I$, va $a_{i j}$ is given by a CES production function that uses inputs of capital and labor from that period, as well as the existing stocks of infrastruc- 
ture." It is assumed that sector $j$ cost-minimizes with respect to capital and labor. Each sector, j, pays value added tax rates on inputs of capital and labor, given by $t_{K i}^{j}, t_{L_{i}}^{j}$, respectively, in period $I$. Thus if $P_{m,}$ and $P_{L i}$ are the prices of capital and labor in period $I$, then the prices charged by enterprises, $P_{1}$, are given by:

$$
\left(P_{i}\right)=\operatorname{va}\left(P, Y_{G i 1}, \ldots, Y_{G i m}\right)(1+t)(I-A)^{-1}
$$

where $v a\left(P, Y_{c i i}, \ldots Y_{G i n}\right)$ is the vector of cost-minimizing nominal value-added per unit of output. value added is a function of the prices of capital and labor, $\mathrm{P}=\left\{\mathrm{P}_{\mathrm{B},}, \mathrm{P}_{1}\right\}$, as well as the vector of public infrastructure types, $Y_{\text {in }}$, which augments the efficiency of value added. The cost of value added is, in turn, increased by capital and labor taxes, $t=\left\{t_{1,}, t_{1 i}\right\}$, which are paid as withholding taxes by the firm. We use the term $(1+t)$ to represent the vector $\left(1+t_{k i}, 1+t_{L i}\right)$. Hence va=va $\left(P, Y_{G i}\right)(1+t)$ represents the vector of total cost of value added for each sector. The term $(I-A)^{-1}$ is the Leontief inverse, based on the input-output matrix, $A$.

The gold mining sector is treated differently from the other sectors in the economy. In particular, gold is not part of the input-output production. Rather, gold output is represented by a Cobb-Douglas production function. 
There are two types of private investment, investment in WA capital, and investment in capital in the rest of Australia. In addition, the governments of both WA and RA invest in infrastructure that augments private production. Private investment is assumed to respond to anticipated future returns on capital, as well as future interest rates. Suppose that $H_{i}=H_{i}\left(y_{k i}, Y_{i=}\right)$ is a neoclassical production function that produces capital using inputs of capital and labor, and which exhibits decreasing

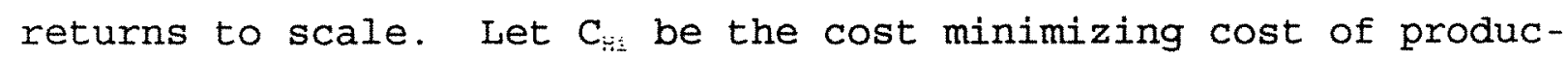
ing the quantity $H_{5}$ of capital. It is assumed that this capital does not begin to yield a return until the period after which it is produced. Accordingly, if $\mathrm{P}_{\mathrm{i}}$ is the price of capital in period $I$, and $r$ the nominal domestic interest rate, then we must have

$$
C_{H i}=\frac{P_{K(i+1)} H_{i}}{1+r_{i}}
$$

where $r_{\text {: }}$ is the interest rate in period $I$, given by:

$$
r_{i}=\frac{1}{P_{B i}}
$$

where $P_{2:}$ is the price of a bond in period $I$. The price of capital is specific to the two parts of the country, so the rate of return to investment differs across the country. 5 


\section{B. Consumption}

There are two types of consumers, representing WA and RA labor. We suppose that both consumer classes have the same demand patterns for goods. The consumers differ, however, in their initial allocations of factors and financial assets.

The consumers maximize intertemporal utility functions. We permit RA-WA migration which depends upon the relative wage rates in the two parts of the country." The consumer has intertemporal budget constraints. He saves by holding money, domestic bonds, and possibly foreign currency. His money demand is interest sensitive. He receives income from factors, and from the interest payments on bonds.

Here, and in what follows, we will use $\mathrm{x}$ to denote a demand variable and y to denote a supply variable. The consumer's maximization problem is thus:

$$
\max U(x), \quad x=\left(x_{1}, x_{L r a 1}, x_{L w a 1}, x_{2}, x_{L r a 2}, x_{L w a 2}\right)
$$

subject to the following constraints:

$$
\begin{gathered}
\left(1+t_{i}\right) P_{i} x_{i}+P_{L r a i} x_{L r a i}+P_{L w a i} x_{L w a i}+P_{M i} x_{M i}+P_{B i} x_{B i}+e_{i} P_{B F i} x_{B F i}=C_{i} \\
P_{K I} K_{O}+P_{A 1} A_{0}+P_{L r a l} L_{r a 1}+P_{L w a l} L_{w a l}+P_{M I} M_{0}+r_{0} B_{0}+P_{B 1} B_{0}+e_{1} P_{B F I} B_{F O}+T R_{1}=N_{1}
\end{gathered}
$$




$$
\begin{gathered}
P_{K 2}(1-\delta) K_{0}+P_{A 2} A_{0}+P_{L r a 2} L_{r a 2}+P_{L w a 2} L_{w a 2}+P_{M 2} x_{M 1}+r_{1} x_{B 1}+P_{B 2} x_{B 1}+e_{2} P_{B E 2} X_{B E 1}+T R_{2}=N_{2} \\
C_{i}=N_{i}
\end{gathered}
$$

$\log P_{M i} x_{M i}=a+b \log \left(1+t_{i}\right) P_{i} x_{i}-c \log r_{i}$

$\log P_{B i} x_{B i}-\log e_{i} P_{B F i}=\alpha+\beta\left(\log r_{i}-\log \frac{e_{i+1}}{e_{i}}\right)$

$$
\log \left(L_{\text {rai }} / L_{\text {wai }}\right)=a_{1}+a_{2} \log \frac{P_{L r a i}-P_{L w a i}}{P_{L r a i}+P_{L w a i}}
$$

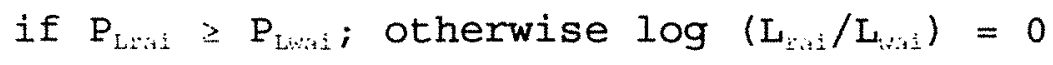

(if the representative household is rural, otherwise labor holdings are constant)

$$
P_{B 2} x_{B 2}=s\left(1+t_{2}\right) P_{2} x_{2}
$$

where:

$P_{i}=$ price vector of consumption goods in period $I$.

$x_{:}=$vector of consumption in period $I$.

$C_{:}=$value of aggregate consumption in period I (including purchases of financial assets).

$\mathbf{N}_{i}$ = aggregate income in period I (including potential income from the sale of real and financial assets).

$t_{:}=$vector of sales tax rates in period $I$. Accordingly, the term $\left(1+t_{i}\right)=\left(1+t_{1 i}, \ldots, 1+t_{N i}\right)$, where there are $N$ intermediate and final goods. 


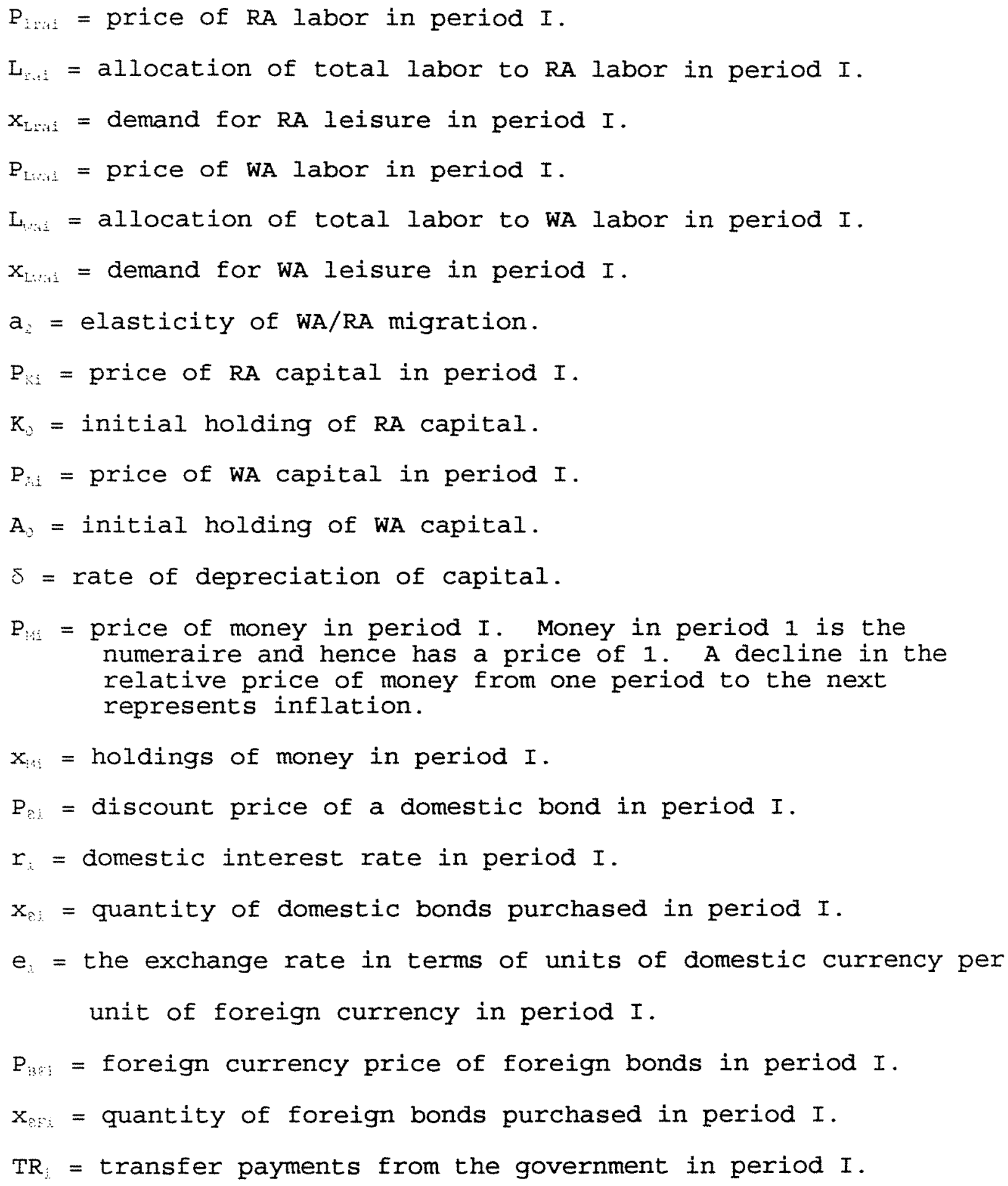


$s=$ the closure savings rate for the economy.

$a, b, c, a_{i}, a_{2}, \alpha, B$ are estimated constants.

Thus the left hand side of the first of the four equations, denoted by (6a), in the consumer's constraint set represents the value of purchases. The next two equations contain the value of the consumer's holdings of capital and labor, as well as the principal and interest that he receives from the domestic and foreign financial assets that he held at the end of the previous period. The equation $C_{i}=N_{i}$ then imposes a budget constraint in each period. Equation $(6 b)$ is a standard money demand equation in which the demand for cash balances depends upon the domestic interest rate and the value of intended consumption. Equation (6c) says that the proportion of savings made up of domestic and foreign interest bearing assets depends upon relative domestic and foreign interest rates, deflated by the change in the exchange rate. Finally, equation $(6 d)$ is a migration equation that says that the change in the consumer's relative holdings of WA and RA labor depends on the relative wage rates.

In the final period of the model we impose an exogenous savings rate, $s$, on the consumers, as in equation (6e). This savings rate is incorporated to determine a closure rule for the economy. Without imposing this or some similar condition, there would be no demand for financial assets in the final period. In practice, we take $s$ to be the long run savings rate for the 
economy. Thus savings rates are endogenously determined in period 1, but are fixed in period 2 .

C. The Government

There are two governments, representing RA and WA. The RA government collects taxes and import duties, and pays for the production of public goods and subsidies. Also, the RA government covers both domestic and foreign interest obligations on public debt. The deficit of the RA government in period $1, D_{i}$, is then:

$$
D_{1}=G_{1}+S_{1}+r_{1} B_{0}+r_{F 1} e_{1} B_{F O}-T_{1}
$$

where $S_{1}$ represents subsidies given in period $1, G_{1}$ is spending on goods and services, while the next two terms reflect domestic and foreign interest obligations of the government, based on its initial stocks of debt. $T_{:}$represents tax revenues.

The resulting deficit is financed by a combination of monetization and domestic and foreign borrowing. If $\Delta y_{3}$ represents the face value of domestic bonds sold by the government in period 1, and $C_{F i}$ represents the dollar value of its foreign borrowing, then its budget deficit in period 2 is given by:

$$
D_{2}=G_{2}+S_{2}+r_{2}\left(\Delta y_{B G 1}+B_{0}\right)+e_{2} r_{F 2}\left(C_{F 1}+B_{F 0}\right)-T_{2}
$$

where $r_{2}\left(\Delta y_{: 01}+B_{i}\right)$ represents the interest obligations on its initial domestic debt plus borrowing from period 1, and 
$e_{2} r_{F 2}\left(C_{F 1}+B_{0}\right)$ is the interest payment on the initial stock of foreign debt plus period 1 foreign borrowing.

The government finances its budget deficit by a combination of monetization, domestic borrowing, and foreign borrowing. As in Feltenstein (1992), we assume that foreign borrowing in period I, $C_{\xi_{1}}$, is exogenously determined by the lender. The government then determines the face value of its bond sales in period $I$, $\Delta Y_{2: i}$, and finances the remainder of the budget deficit by monetization. Hence:

$$
D_{i}=P_{B i} \Delta y_{B G i}+P_{M i} \Delta y_{M i}+e_{i} C_{F i}
$$

The WA government spends on local infrastructure, but, unlike the Federal government, receives only a portion of the taxes generated locally, since most tax collection is done by the Federal government. We model the WA government as receiving all its revenues from revenue sharing from the Federal government. The WA government finances a deficit solely by domestic borrowing, rather than by the additional instruments of monetization and foreign borrowing. Accordingly, a WA deficit leads to debt, rather than monetary expansion.

D. The Foreign Sector and Exchange Rate Determination The foreign sector is represented by a simple export equation in which aggregate demand for exports is determined by 
domestic and foreign price indices, as well as world income. The specific form of the non-mining export equation is:

$$
\Delta X_{n o i}=\sigma_{1}\left[\frac{\Pi_{i}}{\Delta e_{i}+\Pi_{F i}}\right]+\sigma_{2} \Delta y_{w i}
$$

where the left hand side of the equation represents the change in the dollar value of Australian non-mining exports in period I, $\pi_{i}$ is inflation in the domestic price index, $\Delta e_{i}$ is the percentage change in the exchange rate, and $\Pi_{n i}$ is the foreign rate of inflation. Also, $\Delta y_{w i}$ represents the percentage change in world income, denominated in dollars. Finally, $\sigma_{1}$ and $\sigma_{2}$ are corresponding elasticities.

Gold exports are determined separately. We take supply elasticities from Selvanathan (1986) and use them to derive export response. We use Selvanathan's one year "dynamic elasticity" estimates (Table 4.1 op.cit.) to derive a medium term supply response elasticity. Thus the export response of WA gold is endogenously determined based on the domestic currency price change and the assumed supply elasticities.

Demand for imports is endogenous, foreign lending is exogenous. Thus gross capital inflows are exogenous, but the overall change in reserves is endogenous. 
The RA government also attempts to adjust the exchange rate. The supply of foreign reserves $y_{\text {Fis }}$, available to the government in period I is given by:

$$
y_{F G i}=y_{F G(i-1)}+X_{i}-M_{i}+X_{F(i-1)}-X_{F i}+C_{F i}
$$

Here $x_{\text {:i }}$ represents the demand for foreign assets by citizens of $R A$, so $x_{F i-i ;}-x_{F i}$ represents private capital flows. The current account is determined by $X_{i}$, exports, and $M_{i}$, imports. Finally, $C_{F_{i}}$ denotes exogenous foreign borrowing by the home government. As before, the subscript $i=1,2$ denotes the time period.

The RA government has a demand for foreign assets which, we suppose, is determined by an exchange rate rule. Let $\mathrm{y}_{\mathrm{F}}$ represent whatever the government feels to be the critical level of foreign reserves in period I. The government wishes to peg the exchange rate in period $I, e_{i}$, at its level of the previous period, $e_{:-1},$. It will, however, adjust the exchange rate if its stock of reserves, $y_{E: i}$, deviates from its target, $Y_{: i}$. When reserves exceed the government's target, the government leaves the exchange rate as is or revalues it only slightly. When reserves are below the government's target, the government devalues the exchange rate substantially.

IV. Numerical Results

Since our model does not permit an analytical solution, we will use a numerical solution method to derive certain qualita- 
tive conclusions about government policies." we then derive a fixed-point that corresponds to an intertemporal equilibrium. our numerical algorithm determines the prices and quantities that constitute this fixed point, and which, in turn, are the market clearing equilibrium for our model.

\section{A. Calibration and Data Sources}

In order to simulate our model we have used parameter estimates that are derived from a variety of Australian sources. The Australian input-output matrix is taken from Clements and Qiang (CQ) (1995). We have created a $7 \times 7$ matrix, based on their $42 \times 42$ dimensional matrix by adding corresponding rows and columns. The WA input-output matrix was also derived from Clements and Qiang (1995) in a similar manner. The inputs of real value added are taken to be equal to employment in each sector in both the WA and RA matrices. These, in turn, are taken from CQ, Table 2.2. The coefficients of capital and labor in the WA and RA production functions are derived by aggregating shares in the RA input-output matrix given in Table 11 of Australian National Accounts - Input-Output Tables 1989-90, (IO-90) and by a similar aggregation in Table 4.2 in $\mathrm{CQ}$.

Finally, we need to derive coefficients for inter-state trade. We use Lewis (1995), Table 9, to derive inputs into RA from WA by assuming that all exports from WA to RA are used as intermediate inputs to RA production. Import coefficients into 
WA are derived from Interstate and Foreign Trade: Western Australia 1988-89, Table 7 .

Tax rates are assumed to be the same in both parts of the country. Sales tax rates are derived by taking the total commodity and indirect taxes paid by sector, divided by the value of final demand for the sector. These, in turn, are taken from Table 11 (IO-90). Corporate and personal income tax rates are derived from two different sources. The total revenues collected in 1989-90 by the two types of taxes are derived from Reserve Bank of Australia Bulletin (December 1992), Table E.1. The corresponding income from capital and labor is taken from Table 11 (IO-90). We assume the same income tax rates for WA and RA. Federal government spending as a share of GDP is taken from Australian National Accounts - Input-output Tables 1989-90, Tables E.1 and G.6. In the government's production function, we have assumed that factor shares are the same for the RA service sector. Factor shares in the investment functions are taken to be the same as their shares in the RA construction sector.

The demand side of the economy is developed in the following way. We assume that both the WA and RA representative consumers have the same demand parameters. These parameters are then taken to be expenditure shares. We derive these shares from Australian National Accounts - Input-Output Tables 1989-90, Table 11. Initial allocations are derived from several sources. The 
allocations of capital and labor are taken as the 1989-90 value of the returns to capital and labor from I0-90, Table 11. The initial holdings of money are taken as the 1989-90 end of year stock of M1. We divide the holdings of money between the two consumer classes according to the relative sizes of RA versus WA incomes. These stocks are taken from Reserve Bank of Australia: Bulletin (December 1992), Table D1. The stocks of debt are taken to be the outstanding Treasure notes at the end of 1989-90, taken from Reserve Bank of Australia: Bulletin (RBA) (December 1992), Table E.3. Finally, initial holdings of foreign assets by domestic citizens is given by non-official foreign borrowing, taken Erom RBA (June 1994), Table H.6.

We also need certain behavioral parameters. These are those in the money demand equation (6b), the portfolio balance equation (6c), and the migration equation (6d). These parameters were estimated in Feltenstein (1986).

We have incorporated the various estimated parameters described above and have then run the macroeconomic model for the years 1990-91 to 1991-92, taking 1989-90 as the base year. In order to specify an exchange rate regime, we have said that if the level of foreign reserves falls below a target level equal to 3 months of reserves, then the slope of the Central Bank's devaluation is set equal to -2.0 . If the level of reserves rises above the target level, then the Bank revalues with a slope of - 
0.5. Clearly these numbers are for illustrative purposes only. Table 1 gives the results of our base simulation.

Table 1: Base Simulation

(The numbers in parenthesis are historical values) */

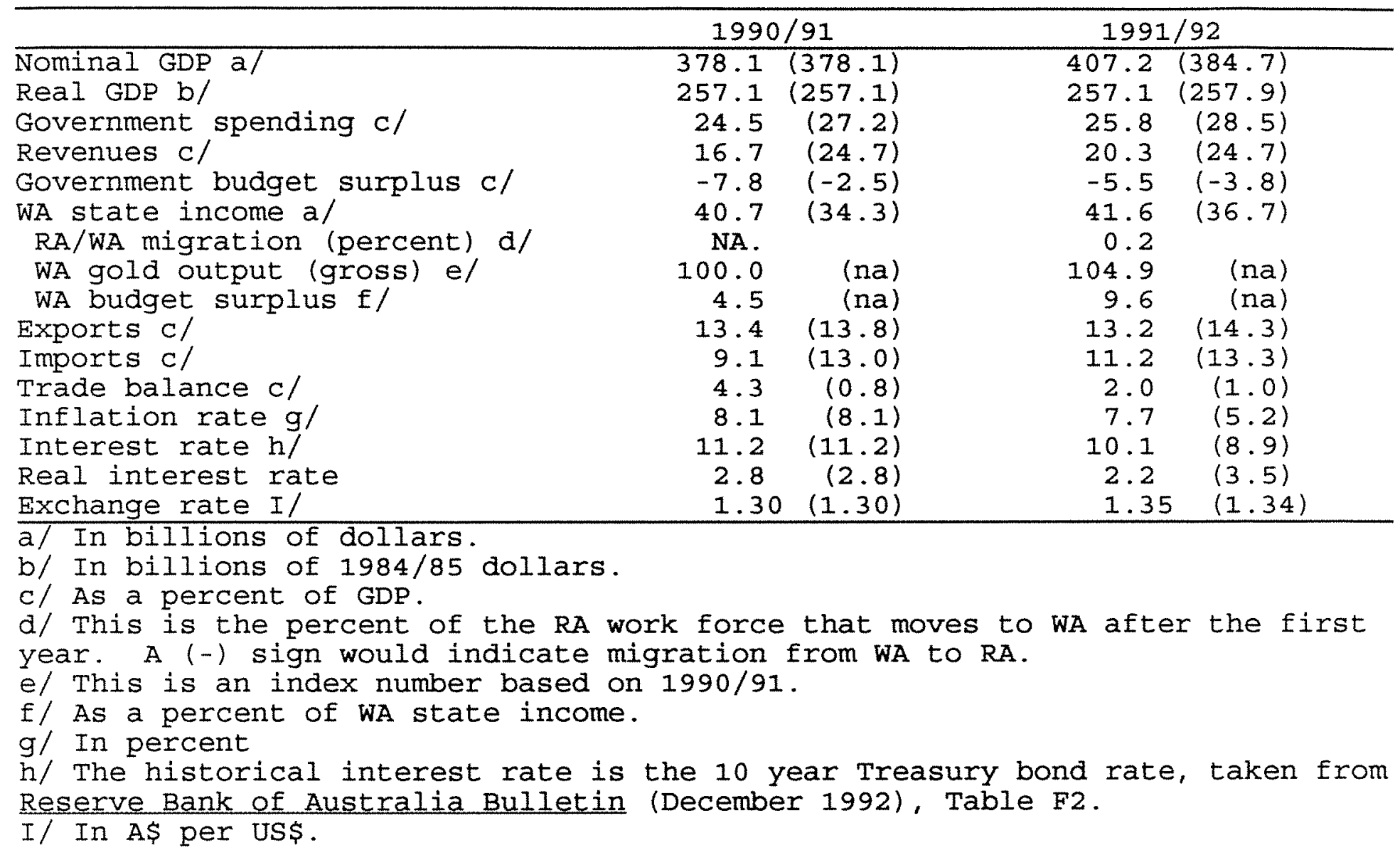

We accurately project the rate of growth of real GDP. However, we underestimate tax revenues. This discrepancy is due to our inclusion of only a limited number of taxes. Our simulated values for the tax revenues of the RA government and for WA state income are reasonably accurate. We are accurate in simu- 
lating the national rate of inflation. Our prediction of national exports is accurate, although imports are low. Interest rates are reasonably accurately predicted.

\section{B. A Gold Tax}

Suppose we now impose a tax on the exports of gold. We will introduce a 2.5 percent tax on gold, paid by producers. The results of this simulation are given in Table 2 .

Table 2: 2.5 Percent Tax on Gold

\begin{tabular}{|c|c|c|}
\hline & $1990 / 91$ & $1991 / 92$ \\
\hline Nominal GDP a/ & 377.3 & 405.8 \\
\hline Real GDP b/ & 257.1 & 256.9 \\
\hline Government spending $\mathrm{c} /$ & 24.4 & 25.8 \\
\hline Revenues c/ & 16.6 & 20.3 \\
\hline Government budget surplus $\mathrm{c} /$ & -7.8 & -5.5 \\
\hline WA state income a/ & 40.6 & 41.4 \\
\hline RA/WA migration (percent) d/ & NA. & 0.2 \\
\hline WA gold output (gross) e/ & 99.5 & 103.7 \\
\hline WA budget surplus $\mathrm{f} /$ & 4.6 & 9.7 \\
\hline Exports c/ & 13.3 & 13.2 \\
\hline Imports c/ & 9.1 & 11.3 \\
\hline Trade balance c/ & 4.2 & 1.9 \\
\hline Inflation rate $\mathrm{g} /$ & 7.9 & 7.6 \\
\hline Interest rate & 11.1 & 10.1 \\
\hline Real interest rate & 3.0 & 2.3 \\
\hline Exchange rate $\mathrm{h} /$ & 1.30 & 1.35 \\
\hline \multicolumn{3}{|c|}{$\begin{array}{l}\text { a/ In bilitions of dollars. } \\
\text { b/ In billions of } 1984 / 85 \text { dollars. } \\
\text { c/ As a percent of GDP. } \\
\text { d/ This is the percent of the RA work force that moves to wA after the first } \\
\text { year. A (-) sign would indicate migration from wA to RA. } \\
\text { e/ This is an index number base on } 1990 / 91 \text { of the Table } 1 \text { simulation. } \\
\text { f/ As a percent of wA state income. } \\
\text { g/ In percent } \\
\text { h/ In As per US\$. }\end{array}$} \\
\hline
\end{tabular}

We observe some interesting changes. Real national income has declined by 0.08 percent by the second year, as compared with 
the benchmark case. The government budget deficit has remained roughly constant in both years. WA state income has declined, along with moderate drops in gold output of 0.5 percent in the first year and 1.1 percent by the second year. The trade balance has deteriorated by 0.1 percent of GDP in both years, compared with the base case. The WA budget surplus has increased. Table 3 presents the results of Table 2 in a slightly different fashion. Here we calculate the percentage change in the relevant variable from the base simulation to the simulation with a tax increase.

Table 3: Percentage Changes Caused by Tax Implementation a/

Nominal GDP

Real GDP

Government spending

Revenues

Government budget surplus

WA state income

RA/WA migration (percent)

WA gold output (gross)

WA budget surplus

Exports

Imports

Trade balance

Inflation rate

Interest rate

Real interest rate

Exchange rate

a/ The numbers represent the percentage changes from Table 1 to Table 2 . Thus some of these percentages are first differences, such as changes in GDP, or shares of GDP. Others are second differences, such as changes in rates of inflation or interest rates.

As a further analysis of our results, Table 4 reports percentage changes in gross real output for each of the WA 
sectors, when Table 2 is compared with Table 1 . This thus gives a disaggregated view of the impact of the tax increase on the real state economy.

Table 4: Sectoral Changes Caused by 2.5 percent Gold Tax a/ $1990 / 91$ $1991 / 92$

Western Australia

Sector 1 Agriculture

2 Mining

3 Manufacturing

4 Electricity

5 Construction

6 Commerce and Services

$-0.1$

$-0.1$

$-0.1$

0.0

$-0.2$

7 Imports from RA

$-0.1$

$-0.1$

$-0.2$

$-0.1$

$-0.1$

0.0

$-0.1$

$-0.1$

$-0.1$

a/ These represent the percentage change in real gross output of each of the seven WA production sectors when the gold tax is implemented.

The tax change has had a small and relatively uniform effect upon sectoral output in WA. Sectoral changes are largely generated by changes in factor prices, which are, in turn, uniform across sectors. Accordingly, the only sectoral differences come from the different structure of costs. Imports from RA decline because of the slight decline in wA state income. We notice that WA sectoral gross (real) outputs decline less than does WA nominal income, as shown in Table 3. The reason for this is that the WA rate of inflation declines as a result of the tax change, just as does the RA inflation rate. Accordingly, the decline in nominal WA income is greater than the real decline, which would essentially correspond to the sectoral changes of Table 4 .

we thus see that the gold tax has had a slight, but largely negative impact upon both the national and WA economies. Indeed, 
the expected national budgetary improvements have not materialized, while RA and WA real incomes have declined. Real interest rates have increased and the trade balance has deteriorated.

V. Summary and Conclusion

We have constructed a dynamic model of the Australian economy that has a regional sub-section representing western Australia. Each part of the economy is represented by distinct technologies, consumer groups and governments. Within the west Australia sub-economy, we have a technology for the gold mining industry as a subset of the aggregate mining industry.

we use estimated behavioral parameters to implement our model. As a first step we show that the estimated model generates a reasonably accurate approximation to actual Australian outcomes for the years 1990-92. We then carry out a simulation in which gold exports are subject to a 2.5 percent tax. The resulting outcome indicates that there is no fiscal improvement at the national level, although the west Australian budget improves. Real income falls both nationally and in west Australia, as reduced gold sales cause the trade balance to decline, and an increased real interest rate causes investment to fall. We conclude that the taxation of gold exports may appear to be a promising source of revenues. However, our results indicate that such taxation leads to few measurable benefits, and, in fact, may have quite negative consequences. 


\section{BIBLIOGRAPHY}

Clements, K.W., and R. Greig (1994), Modeling Large Resource Development Projects in an open Economy: The Case of Austra Iia's North West Shelf Gas Project, studies in Urban and Resource Economics, The Blackstone Company.

Clements, K.W., and Ye Qiang (1995), A New Input-Output Table for Western Australia, Economic Research Centre monograph, Department of Economics, University of Western Australia, June.

Feltenstein, A. (1986), "An Intertemporal General Equilibrium Analysis of Financial Crowding Out: A Policy Model and an Application to Australia," Journal of Public Economics, November, 79-104.

Feltenstein, A. (1992), "Oil Prices and Rural Migration: The Dutch Disease Goes South", Journal of International Money and Finance, n. 11, 273-291.

Harris, J.R., and M. Todaro, "Migration, Unemployment and Development: A Two Sector Model," American Economic Review, March, $42: \quad 329-356$.

Interstate and Foreign Trade: Western Australia 1988-1989, (1990), Australian Bureau of Statistics, Western Australia. Labour Force Estimates (1994), Australian Bureau of statistics. 
Lewis, Eleanor (1995), "Western Australian Interstate and Over seas Exports by Industry," Economic Research Centre discus sion paper, Department of Economics, University of Western Australia, August.

Merrill, Orin H.(1972), "Application and Extensions of an Algorithm that Computes Fixed Points of Certain Non-Empty Convex Upper Semi-Continuous Point to set Mappings", (DoC toral dissertation; Ann Arbor: University of Michigan). Mineral and Petroleum Production: Statistics Digest (1994), Policy and Planning Division, Department of Minerals and Energy, Western Australia.

Minerals Industry Survey: 1993, Australian Mining Industry Council.

Reserve Bank of Australia: Bulletin (various issues), Sydney, Australia.

Scarf, Herbert, with the collaboration of Terje Hansen (1973), The Computation of Economic Equilibria, Cowles Foundation, New Haven.

Selvanathan, Saroja (1986), "An Econometric Study of Gold Production and Prices," Discussion paper \# 86.07, Department of Economics, University of Western Australia, August.

State Accounts: Australian National Accounts, (various issues), Australian Bureau of statistics. 


\section{EOOTNOTES}

1. This paper was written as part of an analysis of the gold mining industry in Australia. Most of the underlying work was carried out while I was visiting the Economic Research Centre of the University of Western Australia. This visit was supported by the Australian Research Council, to whom I would like to express my gratitude. I would like to thank Kenneth Clements and Robert Greig for many suggestions. I would also like to thank Eleanor Lewis and Ye Qiang for assistance.

2. Much of this section is taken from Mineral and Petroleum Production (1994).

3. In our applications, the length of a period is one year. 4. Here and in all subsequent equations the subscript i, referring to a time period, has, unless otherwise specified, the values $i=1,2$.

5. Here, $p_{k}$ differs from WA to RA. We use the same notation for both parts of the country to avoid unreadable subscripts. 6. This approach is motivated by the Harris and Todaro (1970) model. Feltenstein (1992) estimates such a model for Mexico. 7. The first three of these constants are the coefficients of equation (6b), money demand. The next two are the coefficients of migration (the subscripts do not refer to time periods). The 
last two are the coefficients for the portfolio balance equation. 8. In our numerical implementations of Section 4, we use values from Feltenstein (1986) for these behavioral coefficients.

9. We use an iterative algorithm based upon Merrill (1972). 